\title{
EVALUATION OF PRE-HARVEST PRODUCTION FORECASTING OF MUSTARD CROP IN MAJOR PRODUCING STATES OF INDIA, UNDER FASAL PROJECT
}

\author{
Asha Latwal*, Shalini Saxena, S. K. Dubey, K. Choudhary, Seema Sehgal, Neetu and S. S. Ray \\ Mahalanobis National Crop Forecast Centre, DAC\&FW, New Delhi \\ (ashalatwal30, saxenaorshalini9, sunil2949, karanknit, seemasehga193, rathineetu, shibendu.ray)@gmail.com
}

Commission III, Working Group III/10

KEY WORDS: FASAL, Rapeseed-mustard, Maximum Likelihood Classifier, NDVI, Semi-Physical Model, RMSE and t-test.

\begin{abstract}
:
Rapeseed-mustard (Brassica spp.) is the major rabi oilseed crop of India. India is fourth largest contributor of oilseeds and Rapeseed-mustard contributing to around $11 \%$ of world's total production and about $28.6 \%$ in total oilseeds production of the country. More than $85 \%$ Rapeseed-mustard production comes from 5 States viz. Rajasthan [48\%], Haryana [12\%], MP [10\%], UP [9\%] and West Bengal [7\%]. In the previous few years, remote sensing technique has been progressively more considered for evolving as an alternative, standardized, possibly cheaper and faster technology for crop acreage estimation. Furthermore, satellite remote sensing data have strong advantages in comparison with other monitoring techniques because it provides timely, synoptic and latest information of crop at various stages over large scales. Therefore, under FASAL project, cloud free crop season's images of different satellites (Sentinel-2, Resourcesat-2 and Landsat-8) were used and mustard crop was discriminated using Maximum Likelihood Classifier (MLC). Yield was estimated using different methods such as remote sensing derived NDVI, Agrometeorological yield model and Semi-Physical Model. The RMSE values for state level were found to be 4-17\%, 8-19\% and $13-23 \%$ for area, yield and production, respectively. The correlation coefficient (r) between DES and FASAL estimates were close to 0.9 in all the cases. The results of t-test at $5 \%$ level of significance inferred that FASAL and DES results were not significantly different. These results show that RS and weather-based techniques can be effectively used for pre-harvest acreage, yield and production estimation of mustard crop at district, state and national level.
\end{abstract}

\section{INTRODUCTION}

Forecasting Agricultural output using Space, Agro-meteorology and Land based observations (FASAL) is a scheme of Department of Agriculture, Cooperation and Farmers' Welfare, under which; satellite, meteorological and field data are used for district-state-national level pre-harvest crop production forecasting (Ray and Neetu, 2017). Operational forecasts are generated by Mahalanobis National Crop Forecast Centre (MNCFC), in collaboration with India Meteorological Department, State Agriculture Departments and State Remote Sensing Centres by using the procedures developed by the Space Applications Centre of ISRO (Parihar and Oza, 2006). The scheme currently provides the pre-harvest production forecasts for 8 major crops of the country, i.e. Rice (Kharif \& Rabi), Wheat, Sorghum, Sugarcane, Cotton, Jute, Rapeseed \& Mustard and Rabi Pulses (Ray et al., 2016).

Rapeseed-mustard (Brassica spp.) is the major rabi oilseed crop of India. India is fourth largest contributor of oilseeds and Rapeseed-mustard contributing to around $11 \%$ of world's total production and about $28.6 \%$ in total oilseeds production of the country. More than $85 \%$ Rapeseed-mustard production comes from 5 States viz. Rajasthan [48\%], Haryana [12\%], MP [10\%], UP [9\%] and West Bengal [7\%]. In India, these states aggregate to $84.15 \%$ of total Rapeseed \& Mustard acreage and $90.00 \%$ of total production (based on DES data of 2012-13 to 2017-18). Sowing of mustard crop normally starts in the month of September-October and the crop season spreads up to March. Crop requires about $18-25^{\circ} \mathrm{C}$ temperature, low humidity, practically no rains at the time of flowering. It requires high temperature during early growth stages and cool weather and

\footnotetext{
${ }^{*}$ Corresponding Author
}

clear sky during reproductive phase for better development as cloudy weather promotes the incidence of insect-pests. Drought, heat stress, soil salinity and frost are the major abiotic stresses

which determine mustard crop productivity. In Indian mustard, the yield reduction under moisture stress (drought) ranged from 17 to $94 \%$ due to adverse effects on yield components (Prasad, 2014) therefore a fair supply of moisture is essential. The optimum vegetative development takes place at $30^{\circ} \mathrm{C}$, so increase in temperature range and/or low temperatures increased the duration of the vegetative phase which results into low productivity (Venkataraman and Krishnan, 1992).

Pre-harvest crop acreage, productivity and production estimates are very crucial in planning and developmental activities of different government agencies. With the advancement of remote sensing technique, satellite imagery is known to provide valuable information about the features on earth's surface and has become important for pre-harvest crop acreage and production estimation at local, regional or global scale (Sharma, 1991; Patil et al., 2010; Rajak et al., 2016; Subash and Koshal, 2017). Remote sensing, at different spatial resolutions, has also been used for estimation of different crop characteristics e.g. NDVI, leaf area index, biomass, fraction of absorbed photosynthetically active radiation (fAPAR) etc. which are directly related to crop yield (Patel et al., 2006). Additionally, weather variability is an important abiotic stress, which is most harmful as it affects the growth and productivity of crops, resulting in a yield reduction. Generally, about $67 \%$ variation of any crop is governed by prevailing weather condition and 33\% by other crop management factors (Khavse et al., 2014).

Therefore, keeping the above facts in view, every year three pre-harvest production forecasts of Rapeseed \& Mustard $(\mathrm{R} \& \mathrm{M})$ are generated at National/State/District level using remote sensing-based approaches under FASAL project. The 
main objective of this paper is to study the improvement in methodology and to compare the results on year-to-year basis.

\section{STUDY AREA}

The district level area and production estimates are carried out in 6 major Rapeseed \& Mustard growing states of India namely Gujarat, Haryana, Madhya Pradesh, Rajasthan, Uttar Pradesh and West Bengal. In each state, the major districts growing $\mathrm{R} \& \mathrm{M}$ crop are selected for the analysis (Figure 1).

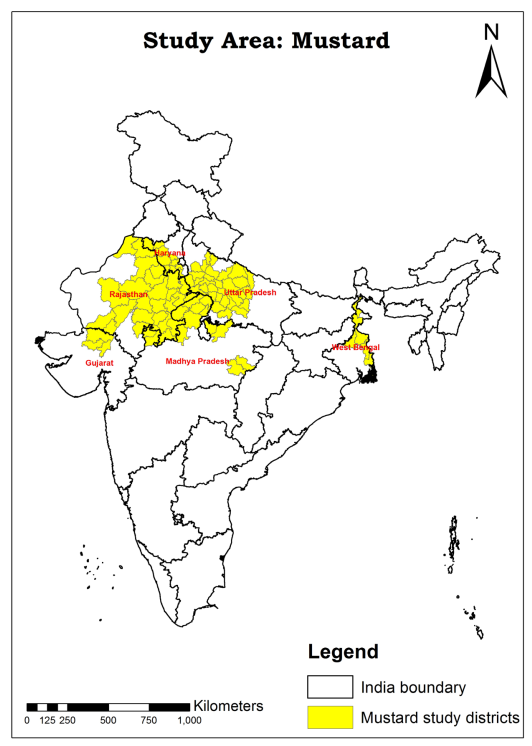

Figure1. Rapeseed \& Mustard growing districts of India under FASAL Project

The state-wise average contribution of R\&M area and production of the country has been shown in Figure 2. Rajasthan state alone is covering $43 \%$ of the total R\&M area while Madhya Pradesh, Uttar Pradesh, Haryana, West Bengal and Gujarat collectively cover $43 \%$ in terms of area.
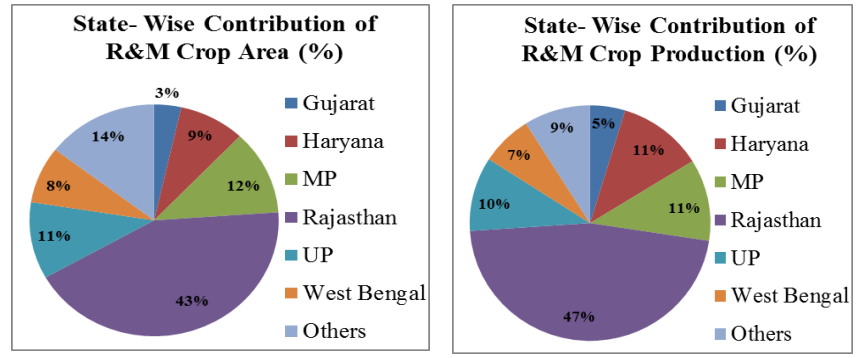

Figure 2. State-wise average (2012 to 2017) contribution to Rapeseed \& Mustard area and production (Source: DES, $\mathrm{DAC} \& \mathrm{FW})$

Rajasthan also occupies the first place in terms of production accounting for $47 \%$ followed by Madhya Pradesh and Haryana contributing $11 \%$ of total production, each, while Uttar Pradesh occupies the third place by contributing for $10 \%$. Thus, the top four states produce about $86 \%$ of total rapeseed \& mustard production in the country.

The district-wise average contribution of $\mathrm{R} \& \mathrm{M}$ area and production of the country has been shown in Figure 3. The highest area was found to be covered by Tonk district of Rajasthan state while production was recorded maximum in Alwar district of Rajasthan.

a.
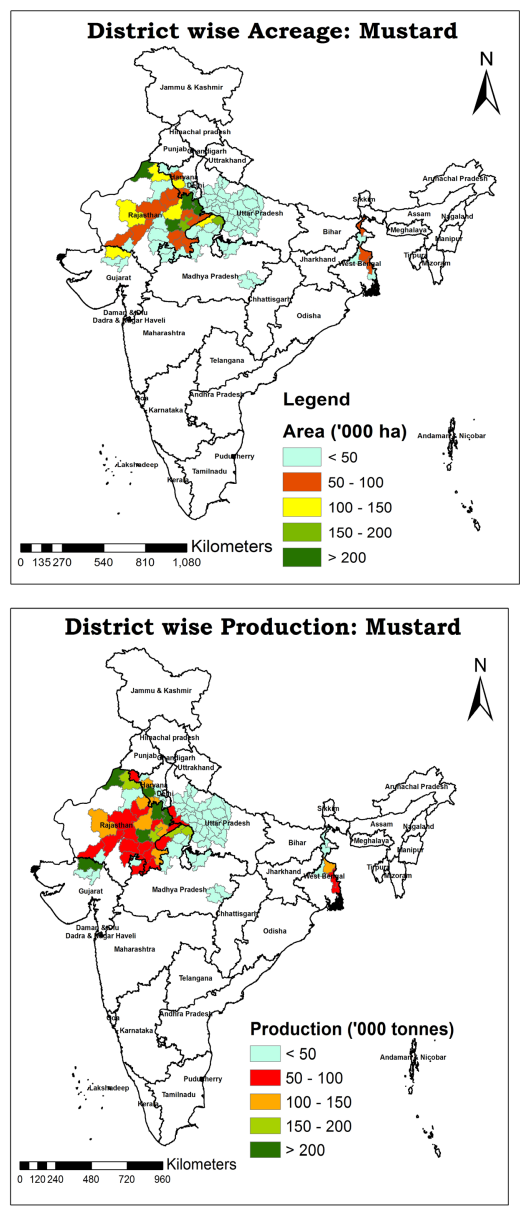

Figure 3. District-wise average (latest 3 years) contribution to Rapeseed \& Mustard area (a) and production (b) (Source: DES, DAC\&FW)

\section{DATA USED}

\subsection{Satellite Data for Acreage Estimation}

Rapeseed \& Mustard area estimation was carried out using Resourcesat-2/2A LISS-III, Landsat-8 OLI and Sentinel-2 MSI data according to the availability of cloud free data for the study districts. The characteristics of remote sensing data have been presented in Table 1 .

\begin{tabular}{|c|c|c|c|c|c|}
\hline Satellite & Sensor & $\begin{array}{c}\text { Saptial } \\
\text { Resolutio } \\
\text { n (m) }\end{array}$ & $\begin{array}{l}\text { Temporal } \\
\text { Resolution } \\
\text { (Days) }\end{array}$ & $\begin{array}{c}\text { Swat } \\
\text { h } \\
(\mathbf{k m})\end{array}$ & Reference \\
\hline $\begin{array}{l}\text { Resourc } \\
\text { esat- } \\
2 / 2 \mathrm{~A}\end{array}$ & LISS-III & 23.5 & $\begin{array}{l}\text { Resourcesat- } \\
\text { 2: } 24 \text { Days } \\
\text { Resourcesat- } \\
\text { 2A: } 12 \text { Days }\end{array}$ & 141 & $\begin{array}{c}\text { NRSC, } \\
2011\end{array}$ \\
\hline $\begin{array}{l}\text { Landsat- } \\
8\end{array}$ & OLI & 30 & 16 & 185 & $\begin{array}{c}\text { USGS, } \\
2016\end{array}$ \\
\hline $\begin{array}{l}\text { Sentinel- } \\
2\end{array}$ & MSI & 10 & 10 & 290 & ESA, 2015 \\
\hline
\end{tabular}

Table 1. Characteristics of remote sensing data 
Landsat- 8 and Sentinel-2 data are available free online while Resourcesat-2/2A is procured from National Data Centre of NRSC. Satellite images during November to February were acquired for acreage estimation of Rapeseed \& Mustard.

\subsection{Satellite Data for Yield Estimation}

3.2.1 Remote Sensing based Empirical Model: Moderate resolution remote sensing data of MODIS (Moderate Resolution Imaging Spectroradiometer) on-board Terra/Aqua Satellite was used for developing remote sensing-based index (Vegetation Condition Index). Historical (in 2017-18, last 11 years' data have been used) fortnightly MODIS Normalized Difference Vegetation Index (NDVI) products $(250 \mathrm{~m}$ resolution), from 2006-2017, were used for computing VCI, as given below (Kogan, 1997).

$$
V C I=\frac{N D V I c u r r-\min N D V I}{\max N D V I-\min N D V I}
$$

Where, NDVIcurr, max NDVI and min NDVI are the values of current period NDVI, maximum and minimum NDVI of historical data, respectively.

3.2.2 Remote Sensing based Semi-physical model: A large set of data has been used for yield estimation using remote sensing based semi physical model and its description has been given below (Table 2).

\begin{tabular}{|c|c|c|c|}
\hline Data /Product & $\begin{array}{c}\text { Satellite/ } \\
\text { Ground }\end{array}$ & Sensor & $\begin{array}{c}\text { Resolutio } \\
\mathbf{n}\end{array}$ \\
\hline $\begin{array}{l}\text { Daily integrated } \\
\text { Insolation }\end{array}$ & INSAT 3D & Imager & $8 \mathrm{~km}$ \\
\hline $\begin{array}{l}\text { 8-days composite } \\
\text { fAPAR }\end{array}$ & Terra & MODIS & $0.5 \mathrm{~km}$ \\
\hline $\begin{array}{l}8 \text {-days composite } \\
\text { surface } \\
\text { reflectance }\end{array}$ & Terra & MODIS & $0.5 \mathrm{~km}$ \\
\hline $\begin{array}{l}\text { Crop (Rapeseed \& } \\
\text { Mustard) } \\
\text { mask }\end{array}$ & Resourcesat & AWiFS & $56 \mathrm{~m}$ \\
\hline Daily Tmin and Tmax & $\begin{array}{l}\text { Gridded } \\
\text { Data of IMD }\end{array}$ & & $\begin{array}{l}0.5 \times 0.5 \\
\text { degree }\end{array}$ \\
\hline 16 days NDVI Profile & Terra & MODIS & $250 \mathrm{~m}$ \\
\hline
\end{tabular}

Table 2. Data details for rapeseed \& mustard yield estimation using semi-physical model

\subsection{Ground Truth Data}

Ground truth (GT) data is essential to discriminate land use/land covers and crop classes in remote sensing data. Ground truth means the information collected about the ground features to relate with data from space. There are basically two main reasons to conduct GTs, (i) To obtain significant data and meaningful information as reference in the analysis of remotely sensed data and (b) To assess the classification accuracy of the technique used for acreage estimation. MNCFC is collaborating with State Agriculture Departments and State Remote Sensing Centres for collection GT information. The GT data is collected by the state agriculture department officials using a smartphone-based Android App, called Bhuvan FASAL, developed by NRSC (ISRO). In each year, the GTs for rapeseed $\&$ mustard crop were collected during December-January and then uploaded to Bhuvan Geoportal. In last 6 years Total 2590
GT points of R\&M crop were collected in study states using in last 6 years. State-wise number of GT points has been demonstrated in Figure 4. The information obtained from GTs indicates that optimum sowing time of R\&M crop is Start of October to End of November. The major growing varieties in study states are GM2, Varuna, Pioneer RH 30, Pioneer 555, Pusa Bold and Bio902.

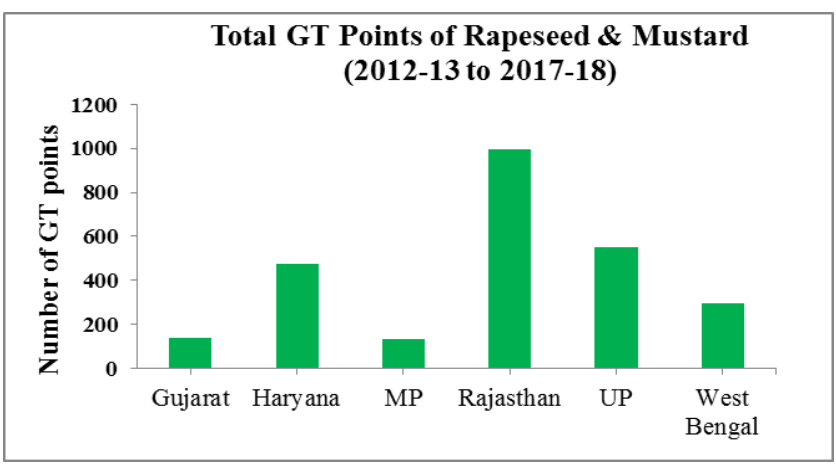

Figure 4. State-wise GT points of Rapeseed \& Mustard (201213 to 2017-18)

\section{METHODOLGY}

\subsection{Acreage Estimation}

Supervised classification methods are based on the external knowledge of the study region which may be derived from field work or ground truth information. Rapeseed \& Mustard acreage estimation includes a two-step process comprising of optimum date selection for acquiring satellite data and supervised classification for area estimation. The Maximum Likelihood Classifier (MLC) is a part of supervised classification scheme and is widely used for identifying different objects on the earth's surface (Lillesand and Kiefer, 2000). Maximum likelihood (MXL) algorithm assumes that the statistics are normally distributed for each class in each band and calculates the possibility that a given pixel belongs to a specific class. Cloud free crop season's images of different satellites (Sentinel2, Resourcesat-2 and Landsat-8) were used during crop growing season (November to February).

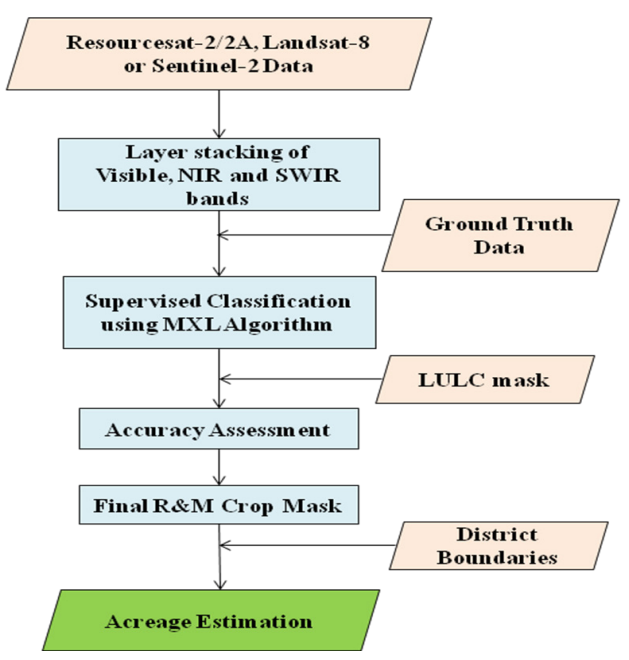

Figure 5. Methodology for R\&M crop acreage estimation using multi-spectral data 
Signatures of R\&M crop and other land cover features are identified using ground truth data, tone, texture, pattern and association from the satellite images and supervised classification was performed to discriminate R\&M crop using MLC embedded in ERDAS Imagine software by taking AOIs (area of interests) of different crops and other land cover features. After the classification, R\&M crop mask is generated and classification accuracy was assessed using ground truth data collected by state government officials. Furthermore, the district boundary has been overlaid on classified image to compute district-level R\&M crop acreage. Additional data used for crop classification include agricultural crop mask, collected from LULC mapping programme of NRSC (NRSC, 2006). Figure 5 shows the descriptive flow diagram of crop classification and acreage estimation.

\subsection{Yield Estimation}

District level R\&M crop yield was estimated using three different procedures: i) Agro-meteorological regression models (Singh et al., 2017), ii) Remote sensing index (VCI) based empirical models (Dubey et al., 2018) and iii) Semi physical Model (Tripathy et al., 2014; Chaurasiya et al., 2017). First approach was used by IMD (in collaboration with state agricultural universities), the second and third approaches were used by MNCFC. The details of all the methods used for yield estimation has been illustrated in Figure 6 .

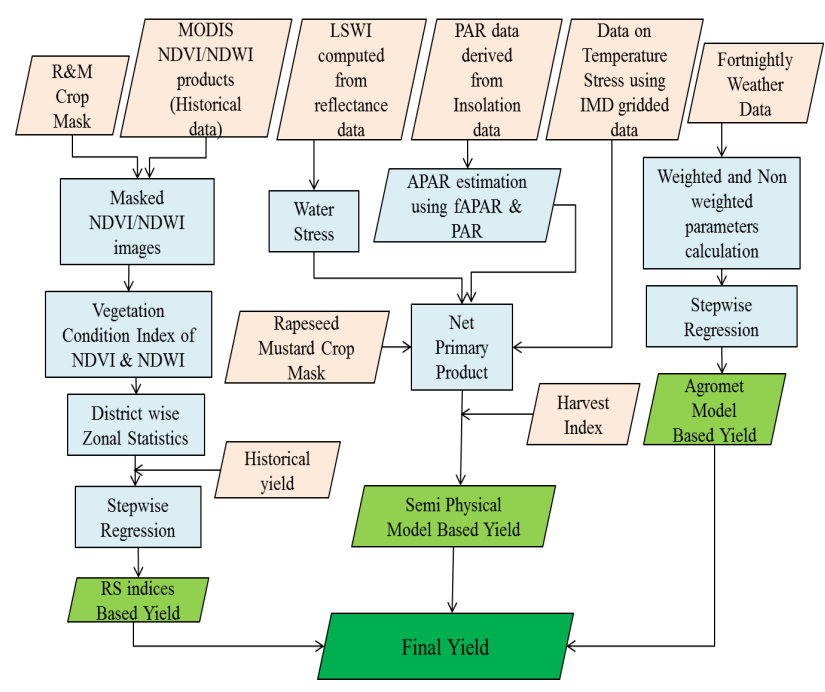

Figure 6. Flow diagram for final yield estimation using different methods

Weather based yield estimation was carried out by IMD using weekly weather (Rainfall, Maximum temperature, Minimum Temperature, Maximum and Minimum Relative Humidity) data of last 10 years. For every year, the data duration for R\&M yield estimation was taken from $2^{\text {nd }}$ fortnight of October to $1^{\text {st }}$ fortnight of February. Step-wise regression technique has been used for developing agrometeorological yield models.

For Remote sensing based empirical model, MODIS NDVI (MOD13Q1 V006, $250 \mathrm{~m}$ resolution) and Normalized Difference Water Index (NDWI) based Vegetation Condition Index (VCI) were computed. For VCI computation, historical NDVI and NDWI data starting from 2006 to predicted year during Rapeseed and Mustard growing period (October $1^{\text {st }}$ fortnight to January $2^{\text {nd }}$ fortnight) were used. Step-wise regression was carried out between DES yield and VCI to obtain district-wise yield values. The third methodology is based on the concept that the biomass produced by a crop is a function of the amount of photosynthetically active radiation (PAR) absorbed, which depends on incoming radiation and the crop's PAR interception capacity. For this, the equation developed by Monteith and Moss (1977) to quantify the fAPAR was used. fAPAR is defined as the fraction of absorbed PAR (APAR) to incident PAR $(0<$ fAPAR $<1)$. The mechanism by which the incident PAR is transformed into dry matter can be written as:

\begin{tabular}{|c|c|c|c|}
\hline \multicolumn{4}{|c|}{$N P P=P A R \times f A P A R \times \varepsilon$} \\
\hline Where, & NPP & $=$ & $\begin{array}{l}\text { Net Primary Productivity or dry matter } \\
\text { accumulation in plant over a period of } \\
\text { time }\left(\mathrm{gm}^{-2} \mathrm{~d}^{-1}\right)\end{array}$ \\
\hline & PAR & $=$ & $\begin{array}{l}\text { Photosynthetically Active Radiation } \\
\left(\mathrm{MJm}^{-2} \mathrm{~d}^{-1}\right)\end{array}$ \\
\hline & fAPAR & $=$ & $\begin{array}{l}\text { fraction of incident PAR which is } \\
\text { intercepted and absorbed by the } \\
\text { canopy (dimensionless) }\end{array}$ \\
\hline & $\varepsilon$ & $=$ & $\begin{array}{l}\text { Radiation use efficiency of absorbed } \\
\text { photo synthetically active radiation } \\
\left(\mathrm{gMJ}^{-1}\right)\end{array}$ \\
\hline
\end{tabular}
Index (HI) and Net Primary Productivity, that is

$$
Y=\sum N P P \times H I
$$

Where, $\mathrm{Y}=$ Yield, $\sum \mathrm{NPP}=$ Total Net Primary Productivity from sowing to harvesting and $\mathrm{HI}=$ Harvest Index

The Harvest Index (HI) values used in this method were taken from the sample Crop Cutting Experiments (CCEs) carried out by MNCFC under the FASAL project. District-level yield estimates, derived from the above three approaches, were combined statistically to get the final yield estimates of Rapeseed \& Mustard Crop.

\subsection{Statistical Analysis}

4.3.1 Relative Deviation/Percent Error: Relative Deviation or Percentage error (R.D./P.E.) is the difference between the estimated and actual values as a percentage of actual one. It can be expressed as:

$$
\text { R.D. / P.E. }=\frac{\left[\left(E_{i}-O_{i}\right)\right] \times 100}{O i}
$$

Where, $E_{i}=$ Estimated Value,

$$
O_{i}=\text { Actual Value }
$$

4.3.2 Correlation Coefficient: Pearson's correlation coefficient (r) is the test statistics that measures the statistical linear relationship between two continuous variables. It is known as the best method of measuring the association as it is based on the method of covariance. It ranges between -1 to + , the value +1 depicts the perfect increasing linear relationship and vice-versa. It is calculated as follows:

$$
r=\frac{\sum_{i=1}^{n}\left(x_{i}-\bar{x}\right) \cdot\left(y_{i}-\bar{y}\right)}{\sqrt{\sum_{i=1}^{n}\left(x_{i}-\bar{x}\right)^{2} \cdot \sum_{i=1}^{n}\left(y_{i}-\bar{y}\right)^{2}}}
$$


4.3.3 Root Mean Square Error (RMSE): The Root Mean Square Error (RMSE) is a frequently used measure of the difference between values estimated by a model and the observed values. The RMSE of a model is defined as the square root of the mean squared error. Lower values of RMSE signify the good accuracy of estimated values.

$$
R M S E=\left\{\frac{1}{n} \sum\left(E_{i}-O_{i}\right)^{2}\right\}^{1 / 2}
$$

Where, $E_{i}=$ Estimated Value, $O_{i}=$ Actual Value, $\mathrm{n}=$ Number of observations

The final RMSE was calculated in percentage as follows: RMSE $(\%)=($ RMSE / Avg. of actual values $) * 100$

4.3.4 Test of Significance: The procedure which is statistically used to examine the differences between two population parameters is known as Test of Significance. It is based upon two hypothesis namely Null $\left(\mathrm{H}_{0}\right)$ and Alternative $\left(\mathrm{H}_{1}\right)$. In the present study Paired t-test was used to check whether the DES and FASAL estimates are same or significantly different.

All these statistical approaches were used to compare DES and FASAL estimates at National, State and District level on the basis of past 6 years dataset.

\section{RESULTS AND DISCUSSION}

\subsection{Rapeseed \& Mustard Classification}

Mean DN (Digital number) values of different crops as observed in multispectral data are given in Figure 7. Rapeseed \& Mustard has higher values in NIR band compared to the other competing crops, such as wheat. This is because during January, R\&M was in peak vegetative stage while wheat was in early vegetative stage, providing higher reflectance in near infrared band.

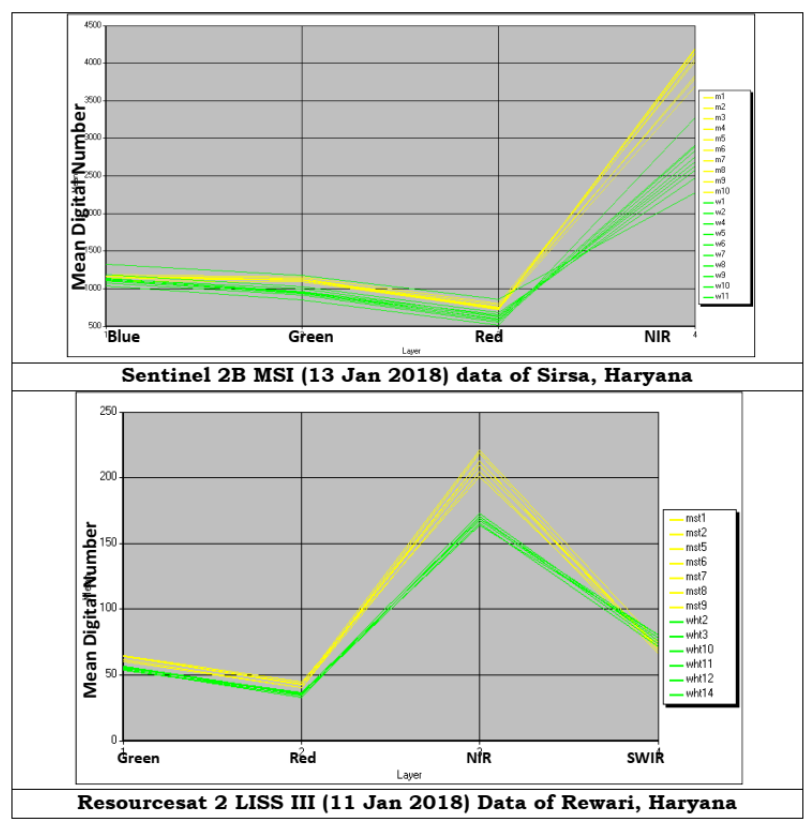

Figure 7: Mean DN values of different crops as seen in multispectral data (Yellow: Rapeseed \& Mustard, Green: Wheat)
The Multi-date NDVI values from Resourcesat-2 AWiFS (56 m resolution) data showed that $\mathrm{R} \& \mathrm{M}$ is early sown and having early peak, compared to wheat (Figure 8). By Mid of February, the NDVI values for R\&M have started declining.

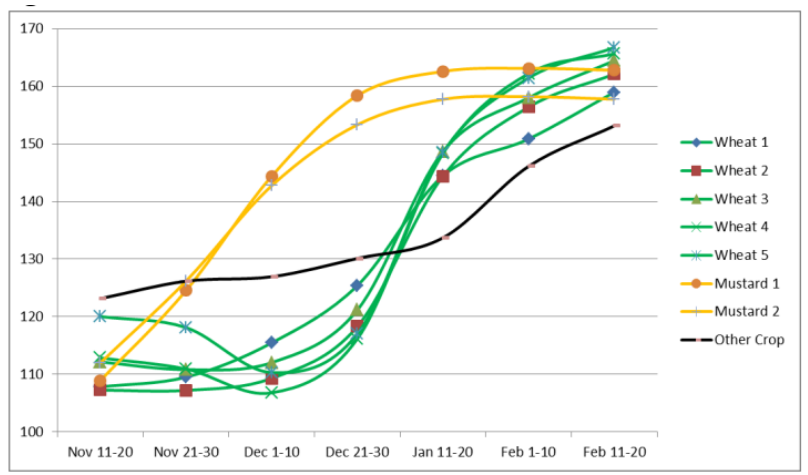

Figure 8: Temporal scaled NDVI [(NDVI+100)*100] pattern of different crops as seen in Resourcesat $2 \mathrm{AWiFS}$ multi-date NDVI data (Yellow: R\&M, Green: Wheat, Black: Other Crop)

The spectral differences between the crops were used for classifying the crops. A typical R\&M classified image is shown in Figure 9, along with the FCC (False Colour Composite) of the Satellite Image, which was used for classifying it. After classifying the crops, the district boundaries were overlaid on the classified maps to generate district level crop area.

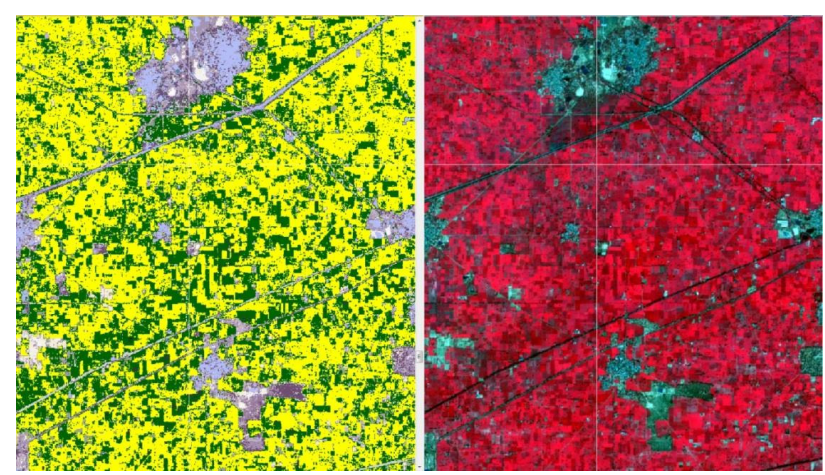

Figure 9. Classified image of Rapeseed \& Mustard and FCC (False Colour Composite) of Mahendragarh District, Haryana (Sentinel 2A MSI, 15 Jan 2018)

\subsection{Accuracy Assessment}

The classification accuracy was assessed with the help of Kappa coefficient, overall accuracy, producers' accuracy and users' accuracy. The detailed information has been shown in Table 3. Total 281 GT points comprising of Mustard and Wheat crop were overlaid on the classified image to test the accuracy. The overall accuracy calculated was $82.21 \%$ with Kappa Coefficient value of 0.627 . These results indicate that remote sensing-based technique can be effectively used for districtlevel acreage estimation. 


\begin{tabular}{lccccc}
\hline Class Name & $\begin{array}{c}\text { Ref. } \\
\text { Totals } \\
\text { (GT) }\end{array}$ & $\begin{array}{c}\text { Classifie } \\
\text { d Totals }\end{array}$ & $\begin{array}{c}\text { No. } \\
\text { Totals }\end{array}$ & $\begin{array}{c}\text { Producer } \\
\mathbf{s} \\
\text { Accurac } \\
\mathbf{y}\end{array}$ & $\begin{array}{c}\text { Use } \\
\text { rs' } \\
\text { Acc } \\
\text { ura } \\
\mathbf{c y}\end{array}$ \\
\hline Unclassified & 0 & 21 & 0 & ----- & ----- \\
Mustard & 82 & 89 & 70 & $85.37 \%$ & $\begin{array}{r}78.6 \\
5 \%\end{array}$ \\
Wheat & 199 & 171 & 161 & $80.90 \%$ & 94.1 \\
& & & & & $5 \%$ \\
Total & 281 & 281 & 231 & & \\
Overall Classification Accuracy $=$ & & $82.21 \%$ & \\
Kappa Coefficient & & & & & \\
\end{tabular}

Table 3. Accuracy Assessment of R\&M crop classification

\subsection{Improvement in Yield Methodology}

The district-level R\&M yield estimation was started in 2013-14 using agro-meteorological yield models. In 2015-16, remote sensing empirical models were used for yield estimation while one more approach i.e. Semi Physical Model has been added to estimate R\&M yield. The comparative analysis showed that yield estimates were more precise after inclusion of different methods as the RMSE value has been decreased from $18.38 \%$ (2014-15) to $10.84 \%$ (2017-18) at district-level.

\subsection{Comparison of FASAL estimates with DES Estimates}

The FASAL estimates are compared with DES estimates at National, District and State-level using different statistical techniques. The results and inferences after the analysis of past 6 year's data have been described below:

5.4.1 National-Level: National-level FASAL estimates of area and production (last 6 years) were analysed statistically with DES estimates. The comparison between DES and FASAL estimates of area and production was done using Relative Deviation (\%) and graphically represented in Figure 10.

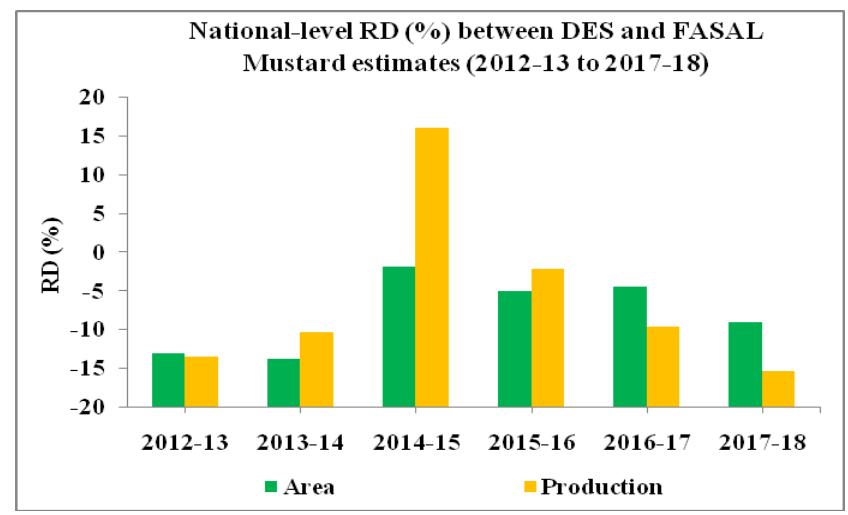

Figure 10: National-level comparison between DES and FASAL Rapeseed \& Mustard estimates

The R.D. values were found in the range of -13.05 to $-1.81 \%$ and -15.34 to $15.97 \%$ for area and production, respectively. The higher positive R.D. was observed in the year 2014-15 which may be attributed to higher values of FASAL estimates in the state of Gujarat and Madhya Pradesh while lower values of
FASAL estimates in Rajasthan and West Bengal during 2017 18 are the reason of higher negative R.D.

5.4.2 State-Level: State-level FASAL estimates of area and production were examined statistically with DES in two ways $v i z$. year-wise and state-wise. The comparison was done using RMSE, Correlation coefficient ( $\mathrm{r}$ ) and t-test. The year-wise and state-wise comparison using RMSE and $r$ has been depicted in Figure 11 and 12, respectively.

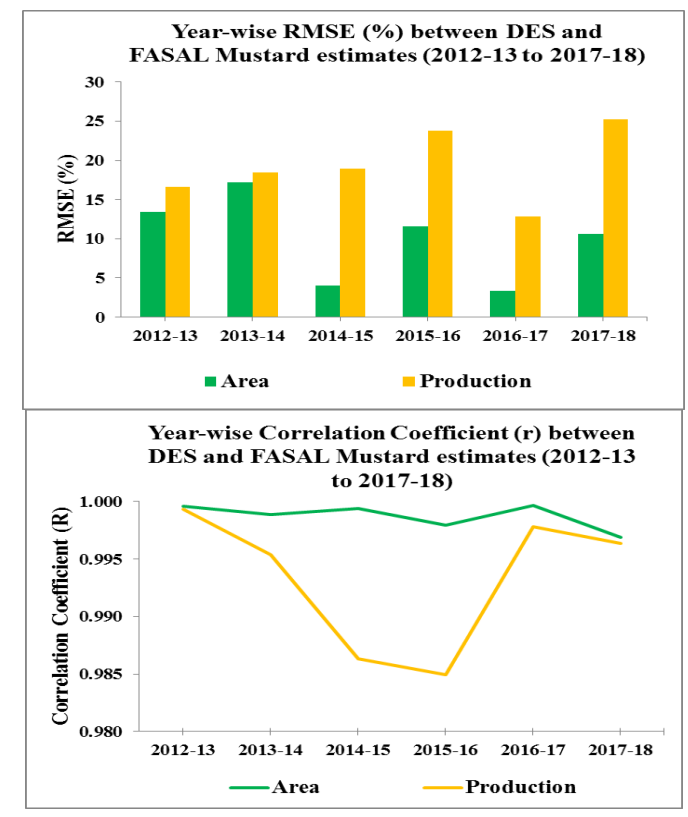

Figure 11: State-level year-wise comparison between DES and FASAL Rapeseed \& Mustard estimates

The year-wise results illustrate that $r$ value is more than 0.97 in most of the years which shows that there is good agreement between DES and FASAL estimates. The higher RMSE in acreage is due to the underestimated FASAL estimates in Rajasthan state (2012-13 and 2013-14) while higher RMSE in case of production is due to lower estimates in Rajasthan and West Bengal during rabi 2017-18.

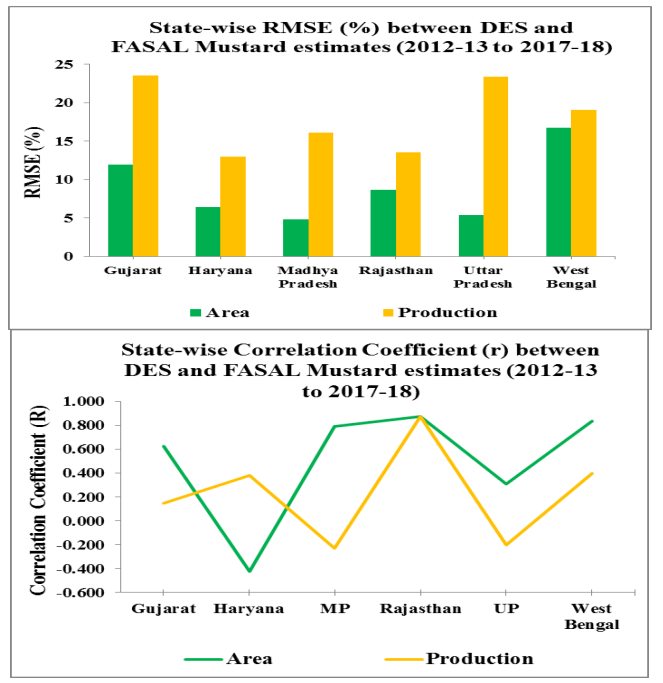

Figure 12: State-level state-wise comparison between DES and FASAL Rapeseed \& Mustard estimates 
In case of state-wise results, $r$ value was computed in the range of -0.4 to 0.8 . RMSE values were obtained in acceptable criteria except in few cases where it is higher especially in case of production which may be due to the error in yield estimates. The results of t-test (at 5\% level of significance) for the year 2017-18 have been presented in Figure 13 and Table 4.

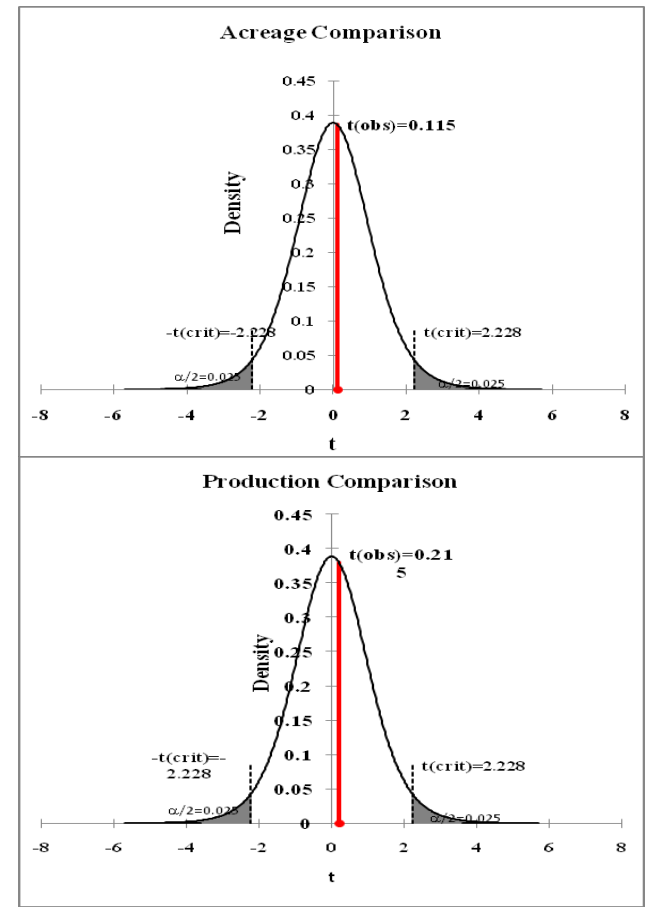

Figure 13: Normally distributed t-curve for state-level comparison of DES and FASAL R\&M estimates (2017-18)

\begin{tabular}{lrrrl}
\hline Estimates & $\begin{array}{c}\text { t- } \\
\text { observed }\end{array}$ & t-critical & p-value & Inference \\
\hline Acreage & 0.115 & 2.228 & 0.911 & $\begin{array}{l}\text { Non- } \\
\text { significan } \\
\text { t } \\
\text { Production }\end{array}$ \\
& 0.533 & 2.228 & 0.605 & $\begin{array}{l}\text { Non- } \\
\text { significan } \\
\text { t }\end{array}$ \\
\hline $\begin{array}{r}\text { Table 4: State-level comparison of DES and FASAL Rapeseed } \\
\text { \& Mustard estimates using paired t-test (2017-18) }\end{array}$
\end{tabular}

The t-observed value falls under the acceptance region of normally distributed t-curve, hence null hypothesis $\left(\mathrm{H}_{0}\right)$ is accepted which indicates that DES and FASAL estimates are not significantly different which further ensure the capability of remotely sensed data for precise estimation of area and production at regional scale.

5.4.3 District-Level: District-level FASAL estimates of area and production were examined with DES using 1:1 scatter line plot and correlation coefficient (Figure 14). The $r$ value was calculated as 0.89 and 0.83 for area and production respectively. It is clear from the figure that all the values are concentrated around the 1:1 scatter line which infers the reliability of geospatial technique for acreage and production estimation at local scale such as district-level.

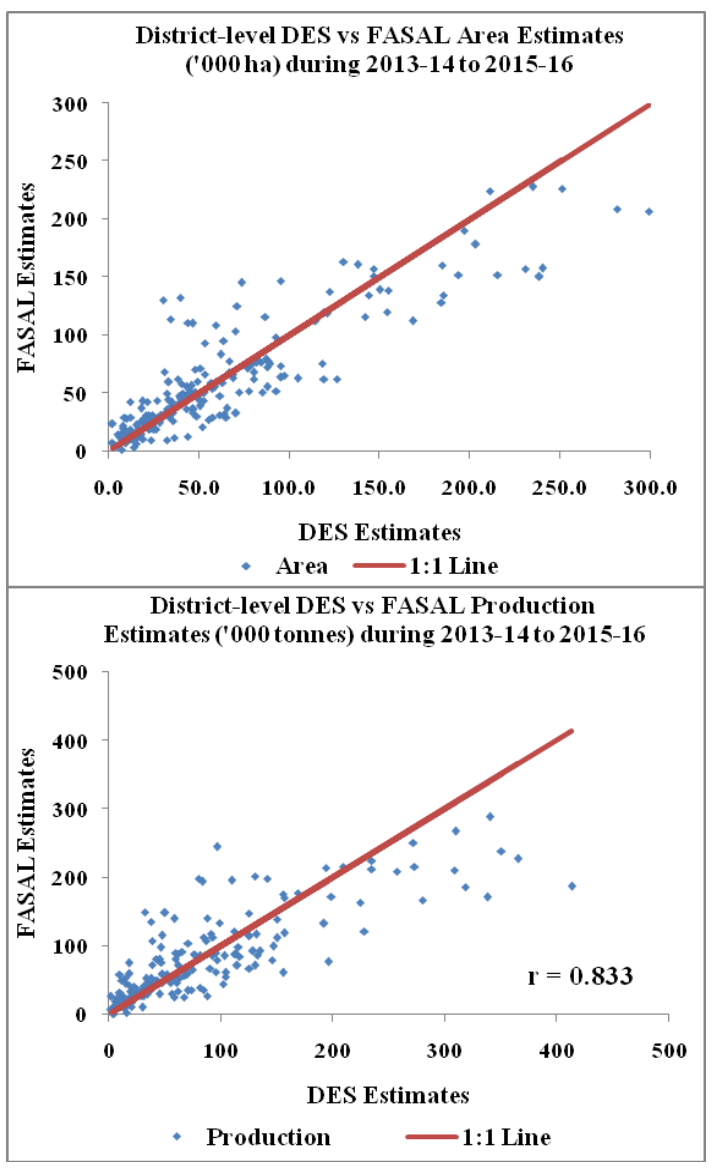

Figure 14: District-level comparison of DES and FASAL Rapeseed \& Mustard estimates

Similar kind of statistical studies have been carried out by Patil et al. (2010), Subash and Koshal (2017) and Li et al. (2011). The results of their studies also show the same differences between actual and estimated values.

\section{SUMMARY AND CONCLUSIONS}

The present study was carried out to examine the usefulness of remote sensing data for acreage and production estimation on the basis of last 6 years dataset. The acreage was estimated using supervised classification (MXL algorithm) and accuracy assessment has been done using ground truth data. Yield was computed by different methods and then final yield has been estimated by giving weightage to each method. DES and FASAL estimates were compared with the help of different statistical measures such as Relative Deviation (R.D.), Correlation Coefficient (r), Root Mean Square Error (RMSE) and Test of Significance. The value of correlation coefficient is more than 0.9 at state-level and 0.8 at district-level. The RMSE values also fall within the acceptable limits which signify the importance and potential of remote sensing data for acreage and production estimation. In addition to MXL algorithm, machine learning techniques based on different algorithms could be useful for acreage estimation at local as well as at regional level. 


\section{ACKNOWLEDGEMENTS}

The crop estimation work has been carried out under the FASAL (Forecasting Agricultural output using Space, Agrometeorology and Land based observations) of Department of Agriculture, Cooperation \& Farmers Welfare (DAC\&FW). The authors are thankful to the senior officials of DAC\&FW, for their strong support and keen interest in the work. The ground truth data collected and expert knowledge provided for remote sensing data analysis by the officials of the State Agriculture Departments and State Remote Sensing Centres, are gratefully acknowledged. The satellite data provided by ISRO (Resourcesat 2 \& 2A), ESA (Sentinel 2), NASA (MODIS \& Landsat-8) and the weather data provided by IMD are thankfully acknowledged. Thanks, are also due to the Analysts of FASAL team, who carried out the annual wheat crop analysis. Thanks are also due to scientists of SAC(ISRO), who developed the procedures for crop estimation under FASAL project.

\section{REFERENCES}

Chaurasiya, G., Saxena, S., Tripathy, R., Chaudhari, K.N. and Ray, S.S., Semi Physical Approach for Sugarcane Yield Modelling with Remotely Sensed Inputs. Vayu Mandal, 43(1), pp. 11-22.

Dubey, S.K., Gavli, A.S., Yadav, S., Sehgal, S. and Ray, S.S., 2018. Remote Sensing-Based Yield Forecasting for Sugarcane (Saccharum officinarum L.) Journal of the Indian Society of Remote Sensing, 46(11), pp. 1823-1833.

ESA, 2015. Sentinel-2 User Handbook. European Space Agency, p. 64.

Khavse, R., Singh, R., Manikandan, N. And Chaudhary, J.L., 2014. Influence of Temperature on Rapeseed-Mustard Yield at Selected Locations in Chhattisgarh State. Current World Environment, 9(3), pp. 1034-1036.

Kogan, F.N., 1997. Global drought watch from space. Bull. Am. Meteorol. Soc., 78, pp. 621-636.

Li, Q., Wua, B., Jia, K., Dong, Q., Eerens, H. and Zhang, M., 2011. Maize acreage estimation using ENVISAT MERIS and CBERS-02B CCD data in the North China Plain. Computers and Electronics in Agriculture, 78, pp. 208-214.

Lillesand, T.M. and Kiefer, R.W., 2000. Remote Sensing and Image Interpretation. John Wiley \& Sons, New York.

Monteith, J.L., and Moss, C.J., 1977. Climate and the efficiency of crop production in Britain. Philosophical Transactions of the Royal Society of London. B, Biological Sciences, 281(980), pp. 277-294.

NRSC, 2006. National Land use and Land cover mapping using multitemporal AWiFS data. NRSA/LULC/1:250K/20062. National Remote Sensing Centre, p. 39.

NRSC, 2011. Resourcesat-2 Data Users' Handbook. NRSC: SDAPSA: NDCNDC: DEC11-364 National Remote Sensing Centre, p. 142.

Parihar, J.S. and Oza, S.R., 2006. FASAL: An integrated approach for crop assessment and production forecasting.
Proceedings of SPIE - The International Society for Optical Engineering 6411.

Patel, N.R., Bhattacharjee, B., Mohammed, A.J., Tanupriya, B. and Saha, S.K., 2006. Remote sensing of regional yield assessment of wheat in Haryana, India. International Journal of Remote Sensing, 27(19), pp. 4071-4090.

Patil, S.S., Patil, V.C. and Al-Gaadi, K.A., 2010. Wheat Acreage, Productivity and Production Estimation through Remote Sensing and GIS Techniques. Aust. J. Basic \& Appl. Sci., 4(8), pp. 3132-3138.

Prasad, R., 2014. Textbook of Field Crops Production Commercial Crops (Volume II). ICAR, New Delhi, pp. 87-99.

Rajak, D.R., Jain, R.K. and Ray, S.S., 2016. Early estimation of crop sown area by integrating multi-source data. Journal of Geomatics, 10(1), pp. 80-88.

Ray, S.S. and Neetu, 2017. Crop area estimation with Remote Sensing. In: J. Delincé (ed.), Handbook on Remote Sensing for Agricultural Statistics (Chapter 5). Handbook of the Global Strategy to improve Agricultural and Rural Statistics (GSARS): Rome, pp. 131-183.

Ray, S.S., Neetu, Manjunath, K.R. and Singh, K.K., 2016. Crop Production Forecasting using Space, Agro-meteorology and Land based Observations: Indian Experience. Presented in International seminar on approaches and methodologies for crop monitoring and production forecasting, 25-26 May 2016, Dhaka, Bangladesh.

Sharma, S.A., Bhati, H.P., Ajai and Nanavaty, S., 1991. Rapeseed-Mustard Acreage Estimation Using IRS LISS-II Data. Journal of the Indian Society of Remote Sensing, 19(1), pp. 59-63.

Singh, K.K., Baxla, A.K., Chattopadhyay, N., Balasubramanian, R., Singh, P.K., Mamta, R., Gohain, G. B., Vishnoi, L. and Singh, P., 2017. Crop Yield forecasting under FASAL (Forecasting Agricultural output using Space Agrometeorology and Land based observations). FASAL Technical Report-2017. India Meteorological Department, Mausam Bhawan, Lodi Road, New Delhi - 110003. 155p.

Subash, N. and Koshal, A.K., 2017. Spatio-temporal analysis for acreage estimation of rabi crops in Uttar Pradesh. 17th Esri India User Conference 2017, pp. 1-12.

Tripathy, R, Chaudhary, K.N., Nigam, R., Manjunath, K.R., Chauhan, P., Ray, S.S. and Parihar, J.S., 2014. Operational Semi-Physical Spectral-Spatial Wheat Yield Model Development. The International Archives of the Photogrammetry, Remote Sensing and Spatial Information Sciences, XL(8), pp. 977-982.

USGS, 2016. Landsat 8 (L8) Data Users Handbook. LSDS1574. Version 2.0. Department of the Interior U.S. Geological Survey, p. 98.

Venkataraman, S. and Krishnan, A., 1992. Crops and Weather. ICAR, New Delhi, pp. 422-423. 